\title{
Marijuana use in hepatitis $C$ infection does not affect liver biopsy histology or treatment outcomes
}

\author{
Theresa Liu MD ${ }^{1}$, Glen T Howell PhD ${ }^{3}$, Lucy Turner PhD², Kimberley Corace PhD ${ }^{1}$, \\ Gary Garber MD ${ }^{1,2,4}$, Curtis Cooper MD FRCPC ${ }^{1,2}$
}

T Liu, GT Howell, L Turner, K Corace, G Garber, C Cooper. Marijuana use in hepatitis $\mathrm{C}$ infection does not affect liver biopsy histology or treatment outcomes. Can J Gastroenterol Hepatol 2014;28(7):381-384.

BACKGROUND: Marijuana smoking is prevalent among hepatitis $\mathrm{C}$ virus-infected patients. The literature assessing the influence of marijuana on liver disease progression and hepatitis $C$ virus antiviral treatment outcomes is conflicting.

METHODS: The authors evaluated hepatitis $C$ virus RNA-positive patients followed at The Ottawa Hospital Viral Hepatitis Clinic (Ottawa, Ontario) from 2000 to 2009. Using The Ottawa Hospital Viral Hepatitis Clinic database and charts, information regarding demographics, HIV coinfection, alcohol use, liver biopsy results, treatment outcomes and self-reported marijuana use was extracted. Biopsy characteristics and hepatitis $\mathrm{C}$ virus antiviral treatment outcomes were assessed for association with categorized marijuana use by adjusted logistic regression; covariates were specified according to clinical relevance a priori.

RESULTS: Information regarding marijuana use was available for 550 patients, 159 (28.9\%) of whom were using marijuana at the time of first assessment. Biopsy fibrosis stage and marijuana use data were available for 377 of these $550(\mathrm{~F} 0-2=72.3 \%)$. Overall, marijuana use did not predict fibrosis stage, inflammation grade or steatosis. Sustained virological response and marijuana use data were available for 359 of the 550 cohort participants; a total of 211 (58.8\%) achieved a sustained virological response. Marijuana use was not associated with premature interruption of therapy for side effects, the likelihood of completing a full course of therapy or sustained virological response. CONCLUSION: Marijuana use did not influence biopsy histology or alter key hard outcomes of hepatitis $\mathrm{C}$ virus antiviral therapy.

Key Words: Antiviral treatment; Cannabinoids; Fibrosis; HCV; Marijuana; Sustained virological response

$A$ high proportion of patients living with chronic hepatitis $C$ virus A (HCV) infection smoke marijuana $(1,2)$. HCV antiviral treatment (pegylated interferon and ribavirin) produces significant neuropsychiatric and physical side effects that can be debilitating and/or lead to dose reduction or discontinuation of therapy. Despite minimal definitive research demonstrating benefit, inhaled marijuana and oral cannabinoids are often used in an attempt to reduce these side effects (1-4). In a cohort of HCV-treated subjects on methadone, inhaled marijuana use was associated with decreased treatment discontinuation and increased sustained virological response (SVR) rates. Similar findings were described in patients using oral cannabinoid medications (3). Despite the possible benefits in combination with HCV therapy, some in vitro and in vivo studies suggest that cannabis increases steatosis rates (5) and fibrosis progression, purportedly by activation of hepatic cannabinoid receptors $(6,7)$.
La consommation de marijuana en cas d'infection par l'hépatite $\mathrm{C}$ n'influe pas sur l'histologie des biopsies hépatiques ou sur les résultats du traitement

HISTORIQUE : La consommation de marijuana est prévalente chez les patients infectés par le virus de l'hépatite $\mathrm{C}$ (VHC). Les publications traitant de l'influence de la marijuana sur la progression de l'hépatite et sur les résultats du traitement antiviral contre le VHC sont contradictoires.

MÉTHODOLOGIE : Les auteurs ont évalué les patients positifs à l'ARN du VHC suivis à la clinique d'hépatite virale de L'Hôpital d'Ottawa, en Ontario, entre 2000 et 2009. Au moyen de la base de données et des dossiers de cette clinique, les auteurs ont extrait de l'information sur la démographie, la co-infection par le VIH, la consommation d'alcool, les résultats des biopsies hépatiques, les résultats des traitements et la consommation avouée de marijuana. Ils ont évalué les caractéristiques des biopsies et les résultats du traitement antiviral contre le VHC pour en dégager l'association avec l'utilisation catégorisée de marijuana au moyen de la régression logistique ajustée. Ils ont précisé les covariables d'après leur pertinence clinique a priori.

RÉSULTATS : Cinq cent cinquante patients avaient fourni de l'information relativement à leur consommation de marijuana, et 159 (28,9\%) en prenaient au moment de la première évaluation. De ces 550 patients, 377 avaient de l'information sur leur stade de fibrose par biopsie et leur consommation de marijuana (F0-2=72,3\%). Dans l'ensemble, la consommation de marijuana n'était pas prédictive du stade de fibrose, du degré d'inflammation ou de la stéatose. Il y avait de l'information sur la réponse virologique soutenue et la consommation de marijuana à l'égard de 359 des 550 participants de la cohorte. Au total, 211 d'entre eux (58,8 \%) ont obtenu une réponse virologique soutenue. La consommation de marijuana ne s'associait pas à l'interruption prématurée du traitement en raison d'effets indésirables ni à la probabilité de terminer un traitement complet ou d'obtenir une réponse virologique soutenue.

CONCLUSION : La consommation de marijuana n'influait pas sur l'histologie des biopsies ou les principaux résultats du traitement antiviral du VHC.

The cannabinoid receptors CB1 and CB2 are G-protein coupled receptors that play a role in the pathogenesis of acute and chronic liver injury (8). CB1 is expressed primarily in the brain and CB2 is expressed in immune tissues (9). Both CB1 and CB2 are expressed elsewhere in peripheral tissues, including endothelial cells. Activation of CB1 receptors in the brain is responsible for the psychoactive effects of marijuana, while CB2 receptors play a role in the underlying pathophysiology of the hepatic and extrahepatic manifestations of chronic liver disease (9). Hepatocyte cannabinoid receptor activation appears to be antagonistic in animal models: CB1 activation in the liver is prosteatogenic and profibrogenic, while hepatic CB2 activation is antifibrogenic (9). This has led to further interest and study of CB1 antagonists and CB2 agonists as potential novel treatment strategies in chronic liver disease.

The relative benefits and risks of cannabis use in HCV infection require evaluation and quantification given the level of uncertainty

${ }^{1}$ University of Ottawa, The Ottawa Hospital Division of Infectious Diseases; ${ }^{2}$ Ottawa Hospital Research Institute; ${ }^{3}$ Carleton University; ${ }^{4}$ Public Health Ontario, Ottawa, Ontario

Correspondence: Dr Curtis Cooper, The Ottawa Hospital - Division of Infectious Diseases, G12-501 Smyth Road, Ottawa,

Ontario K1H 8L6. Telephone 613-737-8924, fax 613-737-8164, e-mail ccooper@toh.on.ca

Received for publication February 26, 2014. Accepted June 9, 2014 
TABLE 1

Liver biopsy recipient characteristics as a function of marijuana smoking status at the time of biopsy

\begin{tabular}{lccc}
\hline & \multicolumn{2}{c}{ Current marijuana smoking } & \\
\cline { 2 - 3 } Characteristic & Yes (n=102) & No (n=275) & P \\
\hline Age, years & $43.9 \pm 9.1$ & $46.7 \pm 8.1$ & $<0.01$ \\
Weight, kg & $76.9 \pm 18.6$ & $78.9 \pm 18.0$ & 0.33 \\
HCV RNA, IU/mL & $2.70 \pm 4.26 \times 10^{6}$ & $2.31 \pm 4.28 \times 10^{6}$ & 0.46 \\
ALT, U/L & $90.3 \pm 69.5$ & $98.0 \pm 96.9$ & 0.44 \\
Male sex & 77.5 & 67.6 & 0.06 \\
HCV genotype & & & 0.02 \\
1 & 81.2 & 67.3 & \\
2 & 4.0 & 9.5 & \\
3 & 14.9 & 14.5 & \\
4 & 0 & 6.2 & \\
Other & 0 & 2.6 & \\
HIV coinfection & & & \\
HIV positive & 13.1 & 10.0 & \\
Race & & & \\
White & 95.6 & 74.5 & \\
Black & 0.0 & 10.9 & \\
Asian & 1.1 & 11.4 & \\
Aboriginal & 3.3 & 3.2 & \\
Immigration status & & & \\
Immigrant & 3.1 & 31.1 & \\
Injection drug use history & & & \\
Yes & 74.5 & 53.1 & \\
Alcohol use & & & \\
>50 g/day at time of & 27.6 & & \\
$\quad$ biopsy & & & \\
\hline
\end{tabular}

Data presented as mean $\pm S D$ or $\%$ unless otherwise indicated. ALT Alanine aminotransferase; HCV Hepatitis $C$ virus

related to the impact on liver histology and antiviral outcomes. To this end, we assessed the influence of inhaled marijuana use on liver fibrosis stage, fibrosis progression rate, inflammation grade and steatosis as determined by liver biopsy. Furthermore, HCV therapy treatment completion rates and SVR rates were evaluated.

\section{METHODS}

A study involving chronic $\mathrm{HCV}$-infected patients followed at The Ottawa Hospital Viral Hepatitis Clinic (Ottawa, Ontario) from 2000 to 2009 was conducted. Using The Ottawa Hospital Viral Hepatitis Clinic database (REB \# 2004-196) and charts, information regarding demographics, HIV and hepatitis B coinfection, excess alcohol use (defined as $>50 \mathrm{~g}$ per day), liver biopsy results, treatment completion as well as self-reported current marijuana use was extracted. Marijuana smoking information was captured at the time of initial clinic assessment using a standardized patient information form completed by the clinic nurse.

The primary outcome measures included fibrosis stage (BattsLudwig system stages F0-F4) on liver biopsy and SVR rates. Secondary outcomes included fibrosis rate (fibrosis stage divided by estimated duration of infection in years), inflammatory grade (grade 0 to 4 ) and degree of steatosis (none, mild, moderate or severe) on liver biopsy as well as HCV antiviral treatment outcome measure (ie, completion of full duration of intended treatment; premature interruption of therapy for virological response futility criteria, side effects, serious adverse events, loss to follow-up, substance abuse).

\section{Statistical analysis}

Demographic characteristics were analyzed descriptively and reported as frequencies and percentages, mean $\pm \mathrm{SD}$, or medians and interquartile range where appropriate. Baseline characteristics between patients reporting marijuana use and those not were compared using $\chi^{2}$ and $t$ tests.
In some cases, patients underwent more than one biopsy or received more than one treatment during the course of the study. For homogeneity across the patient population, only the first biopsy and the first course of HCV antiviral therapy were included in the analysis.

Fibrosis stage, calculated fibrosis progression rate, treatment completion and SVR were assessed for association with categorized marijuana use using adjusted logistic or linear regression. Covariates were specified by clinical relevance a priori. Potential confounders for SVR (genotype, race, age, biopsy stage, viral load, HIV coinfection) and liver biopsy models (sex, race, injection drug use, excess alcohol use, genotype, viral load, HIV coinfection) were adjusted for in the analyses. A backward stepwise procedure was used for model selection. The final model included the set of covariates that were independent predictors of the outcome (as per a Wald test, $\mathrm{P}<0.10$ ). Analyses were performed using SAS version 9.2 (SAS Institute, USA) and SPSS version 22.0 (IBM Corporation, USA).

Overall population

\section{RESULTS}

A total of 550 patients had marijuana use information, of whom $58.3 \%$ $(n=325)$ reported never using marijuana; 159 (28.9\%) were currently using marijuana at the time of initial clinic assessment.

\section{Influence of marijuana smoking on liver biopsy findings}

Of the 550 patients in the cohort, 377 (68.5\%) underwent a biopsy and had marijuana use information available for analysis (Table 1), of whom $102(27.1 \%)$ reported marijuana use at the time of baseline assessment. The median time from first visit to liver biopsies was one month (quartiles: 0, 2 months). Stage 0-2 fibrosis was identified in $72.3 \%$ of those biopsied and $11.4 \%$ were cirrhotic. Marijuana use was not a predictor of biopsy stage (Table 2). Marijuana users did not have more advanced biopsy stage (ie, stage 3-4) compared with participants not currently using marijuana. Advanced fibrosis stage was predicted by age (OR 1.09 [95\% CI 1.05 to 1.13 ]; $\mathrm{P}<0.001$ ), HIV seropositive status (OR 2.63 [95\% CI 1.10 to 6.29]; $\mathrm{P}=0.03$ ) and history of intravenous drug use (IDU) (OR 2.09 [95\% CI 1.20 to 3.67]; $\mathrm{P}=0.01)$ in multivariable binary logistic regression models including genotype, sex, race, excess alcohol use at the time of biopsy ( $>50 \mathrm{~g}$ per day) and marijuana use.

Fibrosis rate was calculated as the fibrosis stage divided by the estimated duration of years infected in the 361 patients with available information. Fibrosis rates were similar between those with and without marijuana use (mean $[ \pm \mathrm{SD}] 0.13 \pm 0.22$ versus $0.11 \pm 0.13 ; \mathrm{P}=0.20$ ).

Overall, marijuana use did not predict biopsy inflammation grade (Table 2). Inflammation grade was correlated with baseline alanine aminotransferase level but not with excess alcohol use at the time of biopsy, sex, race, genotype, HIV status or IDU history (data not shown).

Marijuana use alone was not associated with increased severity of steatosis (Table 2). Genotype 3 predicted higher steatosis levels $(\mathrm{P}<0.001)$. Sex, race, alcohol use at the time of biopsy, HIV status and history of IDU level did not (data not shown).

A quantitative amount (in grams) of smoked marijuana per day was captured in 306 patients at the time of baseline assessment. The percent with biopsy fibrosis stage $\geq 3$ was $21 \%$ in marijuana users compared with $28 \%$ in nonusers $(\mathrm{P}=0.39)$. The proportion of those with high-grade inflammation in biopsy $(18 \%$ versus $14 \%$ with grade $\geq 3)$ was similar in patients with quantitative marijuana use per day data $(\mathrm{P}=0.61)$. There was no difference in the proportion of patients with high-grade steatosis between marijuana users and nonusers. Twentyone patients were classified as high daily marijuana users (defined as $\geq 1$ g per day for marijuana use). Biopsy fibrosis, inflammation and steatosis findings did not differ from those without current marijuana use (data not shown).

\section{Influence of marijuana smoking on $\mathrm{HCV}$ antiviral treatment outcomes}

Of the 550 cohort participants, 379 progressed to initiate interferonbased HCV antiviral treatment (Table 3). Treatment initiation occurred 
TABLE 2

Biopsy findings as a function of current marijuana smoking status

\begin{tabular}{lrrr}
\hline & \multicolumn{2}{c}{$\begin{array}{c}\text { Current marijuana } \\
\text { smoking, \% }\end{array}$} & \\
\cline { 2 - 3 } & \multicolumn{1}{c}{ Yes } & No & P \\
\hline Stage $(n=376)$ & 11.9 & 7.3 & \\
0 & 22.8 & 26.9 & \\
1 & 38.6 & 37.8 & \\
2 & 15.8 & 16.4 & \\
3 & 10.9 & 11.6 & \\
4 & & & 0.75 \\
Grade $(\mathrm{n}=376)$ & 1.0 & 0.4 & \\
0 & 27.5 & 30.7 & \\
1 & 54.9 & 54.7 & \\
2 & 14.7 & 13.5 & \\
3 & 2.0 & 0.7 & \\
4 & & & 0.32 \\
Steatosis $(\mathrm{n}=348)$ & 54.2 & 46.4 & \\
None & 34.4 & 42.9 & \\
Mild $(<30 \%)$ & 7.3 & 8.7 & \\
Moderate $(30 \%$ to $60 \%)$ & 4.2 & 2.0 & \\
Severe $(>60 \%)$ & & & \\
\hline
\end{tabular}

a median six months from the time of baseline marijuana use assessment (quartiles: 3, 14 months). Forty-six of 379 (12.1\%) participants received interferon $\alpha-2 b, 140$ of 379 (36.9\%) pegylated interferon $\alpha-2 a$, 183 of $379(48.3 \%)$ pegylated interferon $\alpha-2 b$ and 10 of $379(2.6 \%)$ albuminated interferon (as part of a clinical trial).

Ninety-six of 379 (25.3\%) HCV antiviral treatment recipients reported marijuana use. SVR was achieved in 51.7\% (45 of 87 ) of marijuana users compared with $61.0 \%$ (166 of 272) of those not actively using marijuana $(\mathrm{P}=0.13)$. Marijuana use was not associated with SVR according to univariate or multivariate binary logistic regression $(\mathrm{P}=0.19)$. The same was found in analyses restricted to HCV genotype 1 and 3 (data not shown). As expected, HCV genotype 1 infection predicted reduced SVR rates $(\mathrm{P}<0.001)$.

Other measures of treatment outcome were compared between marijuana users and nonusers. A complete course of treatment was administered in $60.4 \%$ patients and did not differ according to marijuana use (Table 4). Premature treatment interruptions due to meeting viral stopping rules, adverse events, severe adverse events and substance abuse were similar between groups. Loss to follow-up occurred more frequently in marijuana users (9.4\% [nine of 96]) compared with nonusers (1.8\% [five of 283]; $\mathrm{P}=0.002$ ). The same was found in analyses restricted to HCV genotype 1 and 3 (data not shown). According to multivariate analysis accounting for race, genotype, fibrosis stage and HIV status, marijuana use did not predict treatment completion $(\mathrm{P}=0.33)$.

Data regarding quantitative marijuana use per week were available for 312 of $379 \mathrm{HCV}$ antiviral treatment recipients. All findings were consistent with the above reported outcomes (data not shown).

\section{DISCUSSION}

Patients with chronic HCV infection often use marijuana to help alleviate treatment-related side effects, despite the potential for detrimental effects on the liver. Some studies have suggested that daily marijuana use is an independent predictor of fibrosis progression rate and of severe fibrosis (6). Our analyses did not corroborate these findings, despite the purported proinflammatory effects of CB1 receptor activation by marijuana in the liver $(10,11)$. Similarly, there was no association between inflammation grade or degree of steatosis and marijuana use. This is in contrast to the findings by Hezode et al (5), who reported a twofold increased risk for marked steatosis (defined as
TABLE 3

Hepatitis C virus (HCV) antiviral recipient characteristics as a function of marijuana smoking status at the time of treatment initiation

\begin{tabular}{|c|c|c|c|}
\hline \multirow[b]{2}{*}{ Characteristic } & \multicolumn{2}{|c|}{ Current marijuana smoking } & \multirow[b]{2}{*}{$\mathbf{P}$} \\
\hline & Yes $(n=96)$ & No $(n=283)$ & \\
\hline Age, years & $43.7 \pm 9.3$ & $44.8 \pm 8.9$ & 0.30 \\
\hline Weight, kg & $77.5 \pm 18.8$ & $79.3 \pm 18.3$ & 0.40 \\
\hline HCV RNA, IU/mL & $2.14 \pm 3.29 \times 10^{6}$ & $1.79 \pm 3.33 \times 10^{6}$ & 0.37 \\
\hline ALT, U/L & $100 \pm 73$ & $102 \pm 94$ & 0.83 \\
\hline Male sex & 77.1 & 70.7 & 0.23 \\
\hline Hepatitis C genotype & & & 0.13 \\
\hline 1 & 67.7 & 60.8 & \\
\hline 2 & 5.2 & 13.4 & \\
\hline 3 & 26.0 & 20.8 & \\
\hline 4 & 1.0 & 3.2 & \\
\hline 5,6 & 0 & 1.8 & \\
\hline Biopsy stage & $n=68$ & $n=208$ & 0.98 \\
\hline 0 & 4.4 & 5.2 & \\
\hline 1 & 19.1 & 21.6 & \\
\hline 2 & 44.1 & 41.8 & \\
\hline 3 & 20.6 & 18.9 & \\
\hline 4 & 11.8 & 12.5 & \\
\hline HIV coinfection & & & 0.73 \\
\hline HIV positive & 9.4 & 10.6 & \\
\hline Race & & & $<0.01$ \\
\hline White & 92.0 & 74.4 & \\
\hline Black & 3.4 & 9.4 & \\
\hline Asian & 0 & 13.3 & \\
\hline Aboriginal & 4.6 & 3.0 & \\
\hline Immigration status & & & $<0.001$ \\
\hline Immigrant & 4.3 & 27.7 & \\
\hline Injection drug history & & & $<0.001$ \\
\hline Yes & 74.0 & 53.7 & \\
\hline Alcohol use on treatment & & & $<0.01$ \\
\hline (>50 g/day) & 17.7 & 6.7 & \\
\hline
\end{tabular}

Data presented as mean $\pm S D$ or \% unless otherwise indicated. ALT Alanine aminotransferase

$>30 \%$ ) in those who used marijuana daily. This association remained statistically significant even when controlling for important predictors of steatosis including genotype, alcohol use, body mass index (BMI) and hyperglycemia. It is unclear why our results differ. Subtle differences in definitions (ie, high cut-off point for steatosis and high amount of alcohol consumption to be classified as an excess user in our analysis) and differences in BMI between our Canadian-based and Hezode et al's (5) French-based cohorts may have contributed to the differing outcomes. Unfortunately, we were unable to calculate BMI from the available data in our cohort. We are unable to compare daily marijuana dose and marijuana potency between these cohorts.

Overall, treatment completion rates were not improved in those using marijuana. This contradicts previous reports suggesting that marijuana or oral cannabinoid use increased the duration of time on HCV therapy due to improvement in treatment-related side effects $(3,4)$. We found no evidence for this and, in fact, the loss to follow-up rate was greater in marijuana users. The heterogeneity of outcomes across studies associated with marijuana use may be related to difficultto-control-for measured and unmeasured confounders. As an example, in some cohorts, marijuana use may be a surrogate marker of other illicit drug use/substance abuse, which may contribute to treatment nonadherence. In our cohort, marijuana users were more likely to have IDU histories and/or a history of excess alcohol use.

SVR rates were not increased in marijuana users. This also contradicts findings from previous prospective and retrospective studies that 
TABLE 4

Hepatitis C virus treatment outcomes

\begin{tabular}{lrcc}
\hline & $\begin{array}{c}\text { Current } \\
\text { marijuana } \\
\text { use (n=96) }\end{array}$ & $\begin{array}{c}\text { No marijuana } \\
\text { use (n=283) }\end{array}$ & P \\
\hline $\begin{array}{l}\text { Sustained virological response } \\
\begin{array}{l}\text { Completed full duration of } \\
\text { planned therapy }\end{array}\end{array}$ & $56 / 87(51.7)$ & $166 / 272(61.0)$ & 0.13 \\
$\begin{array}{l}\text { Did not complete entire course of therapy } \\
\text { Met on-treatment viral }\end{array}$ & $173(61.1)$ & 0.76 \\
$\quad 13(13.5)$ & $45(15.9)$ & 0.58 \\
$\quad$ stopping rule & $13(13.5)$ & $49(17.3)$ & 0.39 \\
$\begin{array}{l}\text { Treatment side effect(s) } \\
\text { Serious adverse event }\end{array}$ & $0(0.0)$ & $7(2.5)$ & 0.20 \\
Lost to follow-up & $9(9.4)$ & $5(1.8)$ & $<0.01$ \\
Substance abuse & $4(4.2)$ & $4(1.4)$ & 0.12 \\
\hline
\end{tabular}

Data presented $n / n(\%)$ or $n(\%) .<2$ log drop at 12 weeks, treatment failure at 12 weeks, treatment failure at 24 weeks. Overall $P=0.004$

suggest that cannabis use helps patients remain on therapy longer and achieve better SVR rates $(3,4)$. Our patient population benefits from intensive clinical support from a team of multidisciplinary health care providers focused on managing the physical and mental health complications of HCV antiviral therapy. This may serve to bridge the difference in key HCV treatment outcomes between marijuana nonusers and those using marijuana daily while on therapy. We also believe it is possible that the symptom-alleviating effects of marijuana are simply not sufficiently potent to overcome the most difficult of HCV antiviral treatment side effects. Although hard HCV antiviral treatment outcomes were not influenced by marijuana use, it remains plausible that

\section{REFERENCES}

1. Adlaf EM, Begin P, Sawka E, eds. Canadian Addiction Survey (CAS): A national survey of Canadians' use of alcohol and other drugs: Prevalence of use and related harms: Detailed report. Ottawa: Canadian Centre on Substance Abuse, 2005.

2. Furler MD, Einarson TR, Millson M, Walmsley S, Bendayan R. Medicinal and recreational marijuana use by patients infected with HIV. AIDS Patient Care STDS 2004;18:215-28.

3. Costiniuk CT, Mills E, Cooper CL. Evaluation of oral cannabinoidcontaining medications for the management of interferon and ribavirin-induced anorexia, nausea and weight loss in patients treated for chronic hepatitis $\mathrm{C}$ virus. Can J Gastroenterol 2008;22:376-80.

4. Sylvestre DL, Clements BJ, Malibu Y. Cannabis use improves retention and virological outcomes in patients treated for hepatitis C. Eur J Gastroenterol Hepatol 2006;18:1057-63.

5. Hezode C, Zafrani ES, Roudot-Thoraval F, et al. Daily cannabis use: A novel risk factor of steatosis severity in patients with chronic hepatitis C. Gastroenterology 2008;134: 432-9.

6. Hezode C, Roudot-Thoraval F, Nguyen S, et al. Daily cannabis smoking as a risk factor for progression of fibrosis in chronic hepatitis C. Hepatology 2005;42:63-71. marijuana alleviates on-treatment side effects and increases appetite, thereby reducing patient suffering while on interferon-based treatment.

Several limitations are identified in the present retrospective crosssectional study including incomplete data for several variables. There was unavoidable imprecision in measuring self-reported marijuana exposure. Specifically, quantified marijuana use per day data were not available for all patients included in our cohort. However, sensitivity analyses restricted to patients with quantitative marijuana use per day and to patients with high daily use ( $\geq 1 \mathrm{~g}$ per day) were consistent with the overall reported outcomes related to biopsy findings and HCV antiviral treatment. Nondifferential misclassification of marijuana use results may have lead to a dilution of the measure of association and biased our findings toward the null. Marijuana use data were collected during the initial clinic visit. Although the median time was short between baseline, biopsy and treatment, patterns of marijuana use may have changed over time. Eleven percent of our cohort was HIV coinfected. It is noteworthy that marijuana use was not associated with higher fibrosis stage in HIV-seropositive individuals in our analysis or in others $(12,13)$.

Our analysis did not identify clear benefit or harm attributable to marijuana use on measures of liver histology. Despite the potential benefit of marijuana and oral cannabinoids in alleviating therapyrelated debilitating side effects of pegylated interferon and ribavirin, we did not identify a hard-outcome benefit in patients using marijuana while on HCV treatment. Other long-term health risks and benefits of marijuana use in this population warrant evaluation.

ACKNOWLEDGEMENTS: Dr Cooper is an Ontario HIV Treatment Network Applied HIV Research Chair and a recipient of The Ottawa Hospital Department of Medicine research support.

7. Ishida JH, Peters MG, Jin C, et al. Influence of cannabis use on severity of hepatitis C disease. Clin Gastroenterol Hepatol 2008;6:69-75.

8. Mallat A, Hezode C, Lotersztajn S. Environmental factors as disease accelerators during chronic hepatitis C. J Hepatol 2008;48:657-65.

9. Caraceni P, Domenicali M, Giannone F, Bernardi M. The role of the endocannabinoid system in liver diseases. Best Pract Res Clin Endocrinol Metab 2009;23:65-77.

10. Giannone FA, Baldassarre M, Domenicali M, et al. Reversal of liver fibrosis by the antagonism of endocannabinoid CB1 receptor in a rat model of $\mathrm{CCl}(4)$-induced advanced cirrhosis. Lab Invest 2012;92:384-95.

11. Parfieniuk A, Flisiak R. Role of cannabinoids in chronic liver diseases. World J Gastroenterol 2008;14:6109-14.

12. Brunet L, Moodie EE, Rollet K, et al. Marijuana smoking does not accelerate progression of liver disease in HIV-hepatitis $\mathrm{C}$ coinfection: A longitudinal cohort analysis. Clin Infect Dis 2013;57:663-70.

13. Whitfield RM, Bechtel LM, Starich GH. The impact of ethanol and Marinol/marijuana usage on HIV+/AIDS patients undergoing azidothymidine, azidothymidine/dideoxycytidine, or dideoxyinosine therapy. Alcohol Clin Exp Res 1997;21:122-7. 


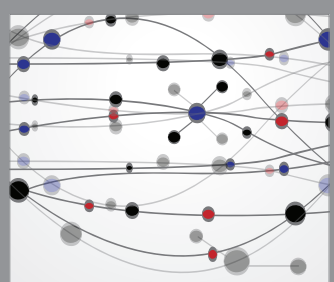

The Scientific World Journal
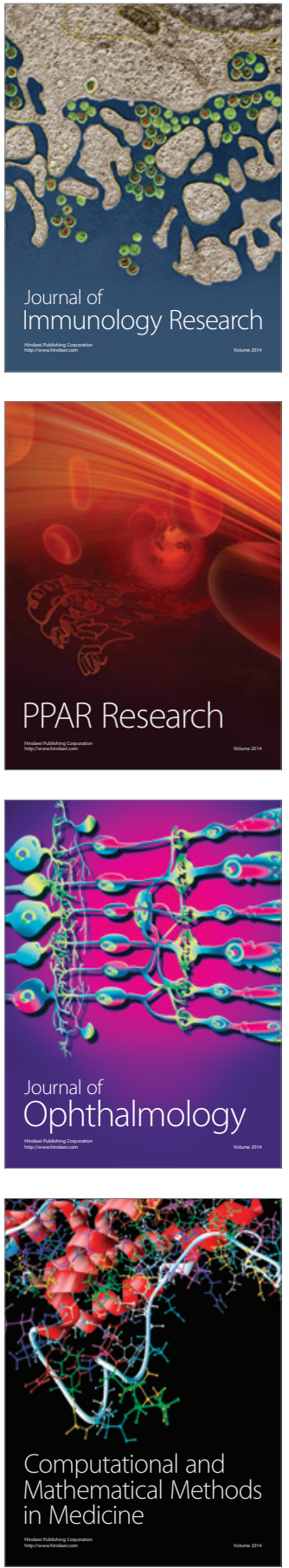

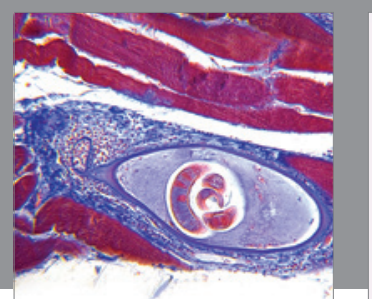

Gastroenterology Research and Practice

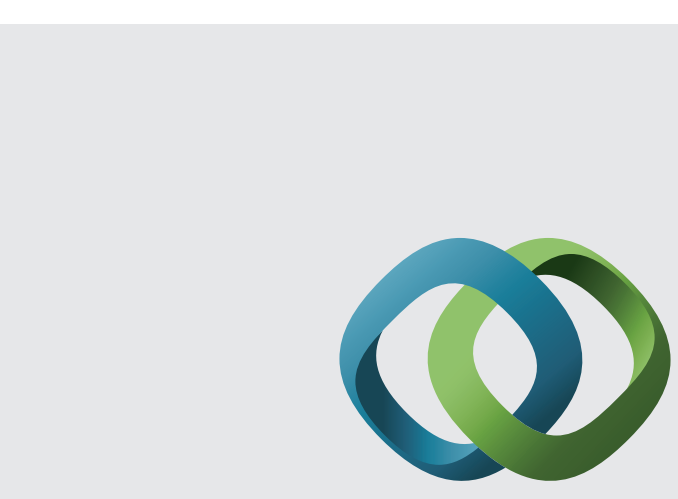

\section{Hindawi}

Submit your manuscripts at

http://www.hindawi.com
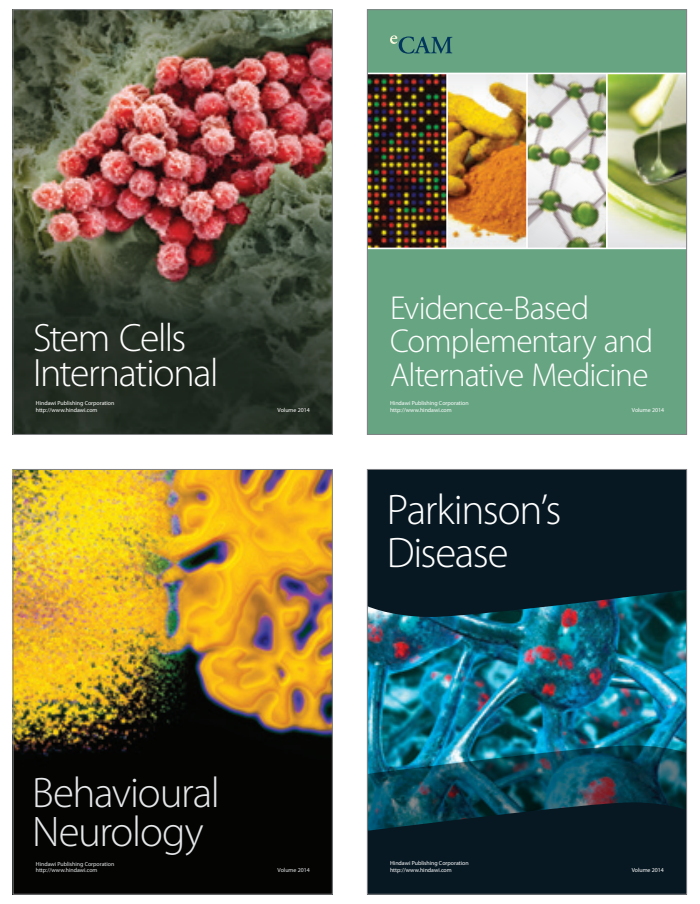
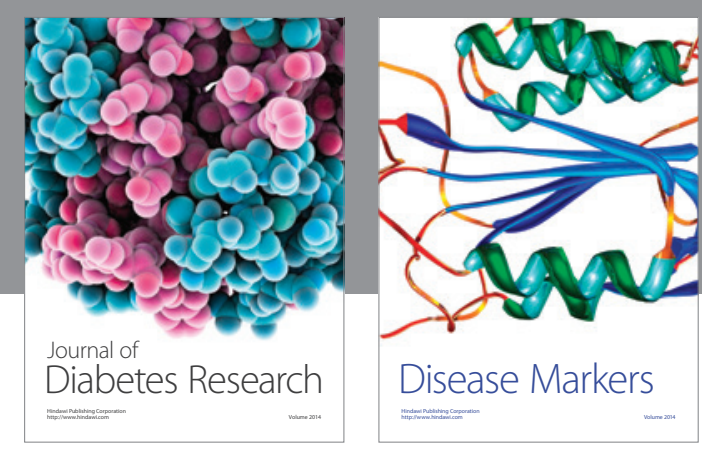

Disease Markers
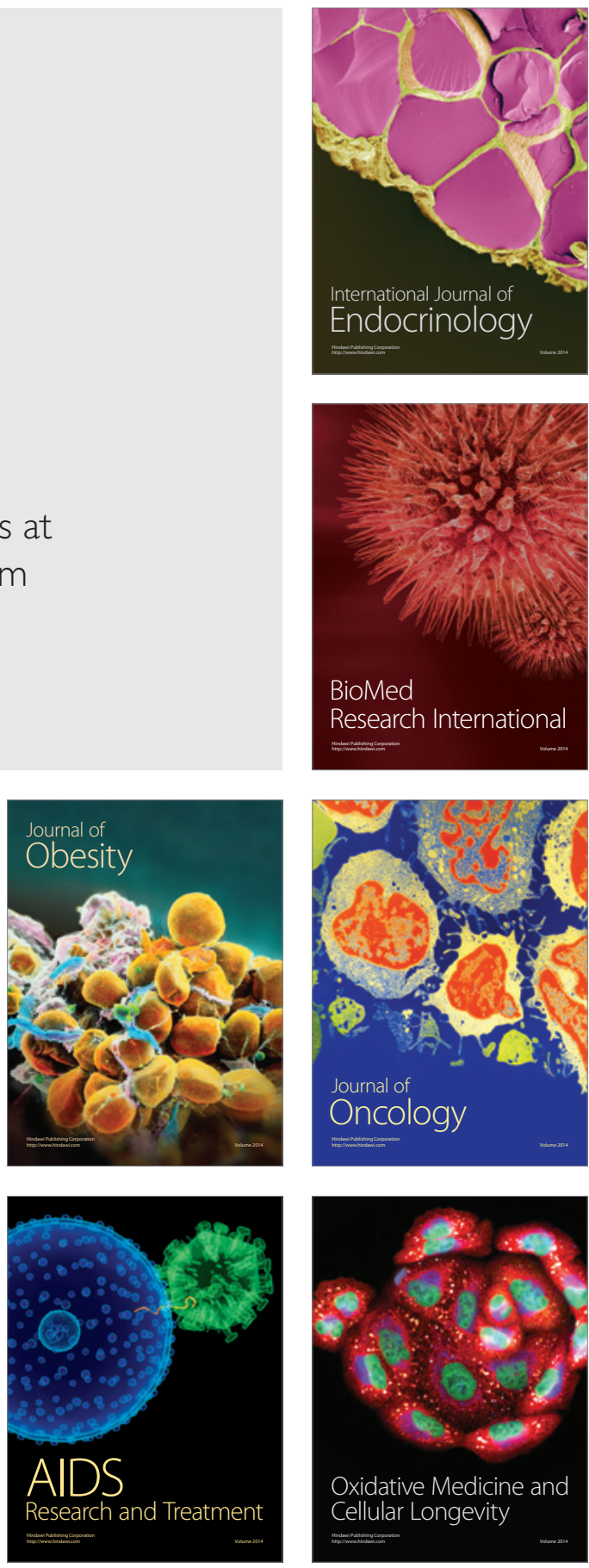